\title{
A Research on Sustainable Micro-Concrete
}

\author{
K. Naga Rajesh, Manoj Kumar Rath, P. Markandeya Raju
}

\begin{abstract}
Construction sector which uses cement in its activities causing a release of $\mathrm{CO}_{2}$ into the atmosphere. Currently, all the sectors are viewing seriously in reducing environmental pollution and hazards. In this scenario, the research in industrial wastes such as fly ash, slag, used foundry sand, marble dust, etc., lead to use in construction industries as sustainable materials (SM), thereby contributing to reduction in environmental pollution. This paper reviewed the usage of these $S M$ in the production of micro-concrete is very less when compared with new age conventional concrete, some of the effects of utilization of these SM in micro-concrete are presented. The quantum of research done in micro-concrete is very less, further studies to be done.
\end{abstract}

Keywords Micro-concrete, Green concrete, Sustainable concrete, Polymer modified micro-concrete

\section{INTRODUCTION}

Micro-concrete (MC) is a mixture of suitably graded sand, cement and water to simulate concrete in small scale models. The cement and sand mixed in dry condition are available in pre-packed bags. It is ready to use dry powder but requires only the addition of water and mixing before application. The required quantity of water is to be added for ensuring the flowability. It is formulated for use in repair works of concrete where placing of conventional concrete is difficult. It should be non-shrink and free flow in nature. As it is prepacked, wastage is less. Application to structural elements is very easy due to its flow nature and finished surface quality is smooth when compared with conventional concrete. The ingredients of MC are not sustainable by themselves. Further, they affect the sustainability of the environment also. The cement used in concrete is also responsible for emitting $\mathrm{CO}_{2}$ into the atmosphere, one Ton of cement releases approximately 0.9 Ton of $\mathrm{CO}_{2}[10,11]$ and construction industry is the second largest producers of $\mathrm{CO}_{2}$ next only to the automobile industry.

Natural deposits like Sand (Fine Aggregate-FA) are depleting very rapidly due to their indiscriminate usage in concrete production. In this regard, there is a huge scope for research in identifying suitable alternatives to concrete ingredients. As per available literature, cement can be partially replaced by industrial wastes like Flyash, GGBS, Waste Glass Powder, Silica Fume, Metakaoline etc. These are also observed to be a suitable partial replacement to cement. Materials that can be adopted as a partial replacement to fine aggregate are Used Foundry Sand

Revised Manuscript Received on July 10, 2019. Professor, Department of Civil Engineering, GMRIT, Rajam. Andhra Pradesh, India. (rajeshkanta@gmail.com)

Manoj Kumar Rath, Corresponding author, Professor, Department of Bhubaneswar. Odisha India. (manojkumar.rath@cutm.ac.in)

P. Markandeya Raju, Professor \& Head, Department of Civil Engineering, MVGR College of Engineering (A), Vizianagaram. Andhra Pradesh, Iindia. (markandeyaraju@ yahoo.com)
K. Naga Rajesh, Research Scholar, CUTM, Odisha, Assistant Civil Engineering, Centurion University of Technology \& Management,

(UFS), $M$ sand (MS), Marble Powder (MP), Granite Powder, Pond ash, etc., [12, 13]

Based on encouraging results of various researches, the usage of green materials in the manufacturing of concrete thereby contributing to the reduction of environmental pollution was initiated in the recent past. The objective of this paper is to present a review of the micro-concrete manufactured with sustainable materials like fly ash, GGBS, quartz sand, limestone, Marble Powder, Granite Powder, Pond ash, etc.

\section{REVIEW OF LITERATURE \& RESULTS}

Fly ash and Ground Granulated Blast Furnace Slag (GGBS) are some of the by-products of iron and steel manufacturing industry collected from blast furnace as shown in Figs. 1 and 2. The stress-strain behaviour was studied by varying the type and size of aggregate in concrete and MC. It was found that with an increase in size and roundness of aggregates, compressive and tensile strength decreased [1].

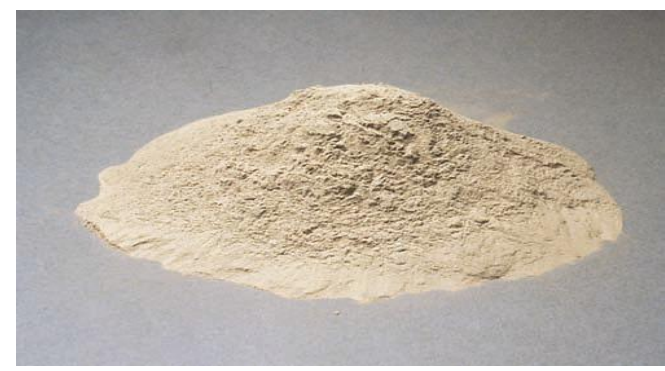

Fig. 1. Fly ash

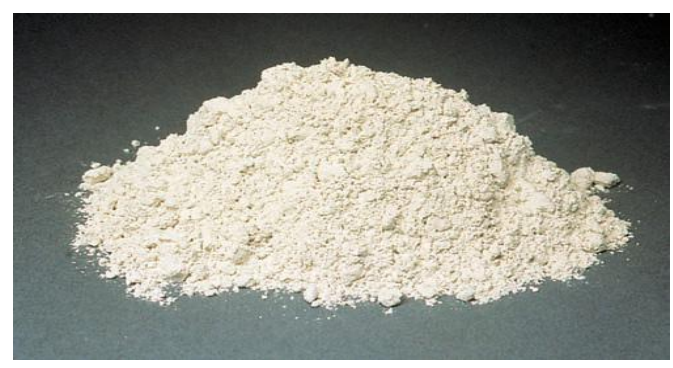

Fig. 2. GGBS

The concrete panels manufactured with reinforced microconcrete, unreinforced micro-concrete and ferrocement were analyzed using probabilistic approach i.e., Weibull model. The strength of the panel depends on defects in microstructure level, loading and size of the structure. The ferrocement panels tested for multiple cracking in tension was predicted based on unreinforced MC tested in flexure. The heterogeneous stress effect on unreinforced and

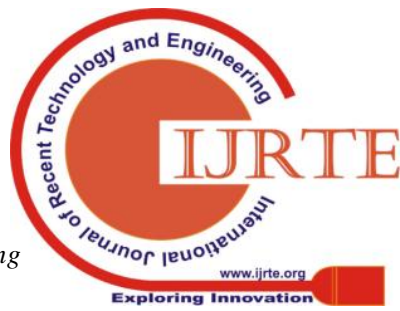




\section{A Research on Sustainable Micro-Concrete}

reinforced MC was studied based on the Weibull model. The fracture properties of unreinforced MC was analyzed based on macroscopic stress parameters [2].

MC manufactured with micro-aggregates i.e., quartz sand, river sand and limestone (size varies from $0.5 \mathrm{~mm}$ to $1 \mu \mathrm{m}$ ) as shown in Figs. 3 and 4 have improved the particle packing density in the cementitious system along with significant enhancement in rheological and mechanical properties. The micro-aggregates used in $\mathrm{MC}$ can be characterized based on the "fineness index"[3].



Fig. 3. SEM images of micro-aggregates - quartz sand

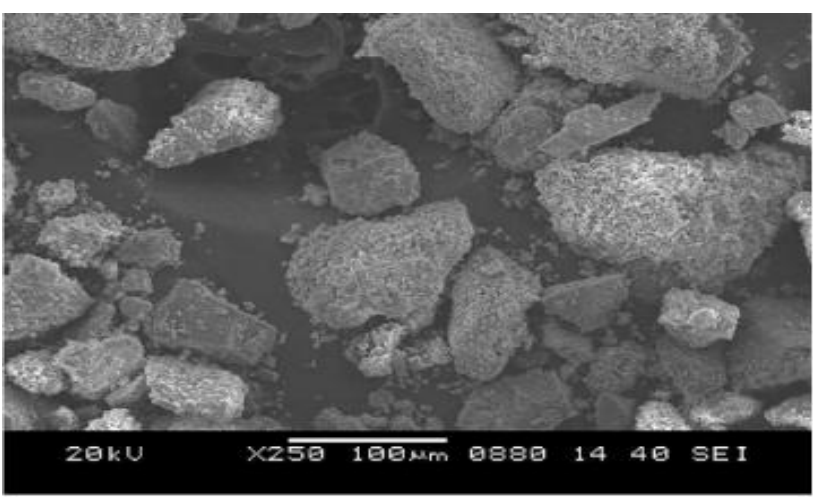

Fig. 4. SEM images of micro-aggregates - limestone

In aggressive environments, for repairing and rehabilitation of concrete structures it was concluded that polymer modified concrete (PMC) was economical when compared with fibre-reinforced polymer concrete (FRP) because of its resistance to moisture, good early strength and high durability $[4,14]$.

In self-compacting micro-concrete composites, composite fibres (polypropylene-PP and polyvinyl alcohol-PVA) are used. The cement matrix and properties of fibre play a key role in attaining the strength. The performance of these fibres was studied by the author in different matrices of MC manufactured with and without fly ash. It was concluded that high strength cement matrix with a high strength composite fibre exhibited high performance in terms of flexural strength and toughness. Addition of fly ash has not shown any significant reduction in the strength of self-compacting micro-concrete composites because fly ash was very fine and filled the voids present in the cement matrix [5].

Concrete filled tubular columns (CFT) is having a high "axial load carrying capacity". In tall buildings and bridges, CFT's are used because of high ductility, good static and dynamic impact properties. The steel tubes filled with micro-concrete were experimentally studied under impact load at an elevated temperature of $400^{\circ} \mathrm{C}$ using "split Hopkinson pressure bar". It was experimentally proved and validated with test results that the CFT's have high impact resistance at elevated temperature. [6].

Concrete matrix (mortar matrix, aggregates and pores) behaviour is studied in mesoscale as the macro strength of same depends on microstructure properties. Micro-concrete specimens are prepared to highlight the failure mechanisms of mechanical and morphological properties. X-ray scanner and X-ray tomography (result was input to "3D-FE Meso model") was used and concluded that 3D mesoscale model can predict the failure patterns and macroscopic behaviour of the material [7].

Bond strength of Micro-concrete was investigated with substrate concrete surfaces in perpendicular, parallel and inclined directions by applying a load in respective directions. It was found that in tensile and flexure test, MC has shown independent behaviour when compared with substrate concrete. But in the compressive and shear test, $\mathrm{MC}$ has shown dependent behaviour with the substrate [8].

MC with sintered fly ash as a fine aggregate (sizes 4 to 8 $\mathrm{mm}$ ) has low density when compared with conventional MC. Sand was replaced by weight with sintered fly ash at various percentages i.e., 50, 60, 70 and 100 in MC. It was observed that drying shrinkage in temperature variation of non-conventional MC was within permissible limits. The compressive, flexural and flexural bond strengths of B-type $\mathrm{MC}$ has shown comparable results with conventional MC. The E-type MC has shown very less drying shrinkage value compared with conventional MC [9].

\section{CONCLUSIONS}

- The compressive strength in case of extremely ground limestone and quartz was not in line with flexural strength due to the surface roughness of ground limestone in fresh MC.

- It is not easy to place conventional concrete at inaccessible repair zones. Polymer modified MC, due to its free flow, self-levelling, high early strength can be easily placed and is preferred generally.

- PVA fibres in micro-concrete improved flexural strength and toughness, whereas PP fibres initially slipped from the matrix. But after addition of fly ash they showed improved frictional bond between the matrix and PP fibres.

- Steel tubes filled with MC performed well under impact loads and elevated temperatures $\left(400^{\circ} \mathrm{C}\right)$.

- MC with higher compressive strength showed higher bond strength with substrate concrete when tested.

- With 60-70\% of sintered fly ash aggregate in MC, there was an increase in flexural bond strength. When compared with conventional MC, the demand for water increased with increase in replacement percentage. 


\section{SCOPE FOR FUTURE STUDY}

Most of the research on sustainable materials are showing good results in mechanical and durable properties when compared with conventional concrete. However, there is a need for more research in finding the effectiveness of utilizing sustainable materials in micro-concrete. Furthermore, the scope in durability aspects is to be studied extensively.

\section{REFERENCES}

1. B. P. Hughes, B. Sc, and D. Ph, "The deformation of concrete and micro- concrete in compression and tension with particular reference to aggregate size," in Magazine of Concrete Research, 1966, Vol. 18, No. 54, pp. 19-24.

2. A. Rita, C. Silva, and S. P. B. Proenc, "Probabilistic Approach to Predict Cracking in Lightly Reinforced Micro concrete Panels '," J. Eng. Mech., Vol. 130, No. 8, pp. 931-941, 2005.

3. B. Felekog, "Effects of PSD and surface morphology of micro-aggregates on admixture requirement and mechanical performance of micro-concrete," Cem. Concr. Compos., Vol. 29, pp. 481-489, 2007.

4. S. C. Pattanaik, "Structures with Polymer Modified Concrete," in Rehabilitation and Retrofitting of Structures, 2009.

5. B. Feleko, K. Tosun, and B. Baradan, "Effects of fibre type and matrix structure on the mechanical performance of self-compacting micro-concrete composites," Cem. Concr. Res., Vol. 39, pp. 1023-1032, 2009.

6. J. Huo, Q. Zheng, and B. Chen, "Tests on impact behaviour of micro-concrete-filled steel tubes at elevated temperatures up to $400^{\circ}$ C," Mater. Struct., Vol. 42, pp. 1325-1334, 2009.

7. O. Stamati, E. Roubin, E. Ando, and Y. Malecot, "Tensile failure of micro-concrete: from mechanical tests to FE meso-model with the help of X-ray tomography," Meccanica, 2018.

8. D. Nayak, R. R. Pattnaik, K. C. Bhoi, and B. C. Panda, "Investigation into Material Strength and Direction of Applied Forces to Assess Bonding Behaviour of Microconcrete," J. Inst. Eng. Ser. A, 2018.

9. K. C. Bhoi and R. R. Pattnaik, "Investigation into lowdensity fly ash aggregate in micro concrete for lightweight concrete repair," J. Build. Pathol. Rehabil., Vol. 3, No. 10, pp. 1-9, 2018.

10. EPA (Environmental Protection Agency), Available and Emerging Technologies for Reducing Greenhouse Gas Emissions from the Portland Cement Industry, Washington D.C., (2010)

11. USGS (US Geological Survey), Background Facts and Issues Concerning Cement and Cement Data, Reston, $\mathrm{VA},(2005)$

12. Vinita Vishwakarma and D. Ramachandran, Green Concrete mix using solid waste and nanoparticles as alternatives - A review, Construction and Building Materials, Vol. 162, 96-103 (2018)

13. K. M. Liew, A. O. Sojobi and L. W. Zhang, Green concrete: Prospects and challenges, Construction and Building Materials, Vol. 156, 1063-1095 (2017)

14. Subhas ChSahoo M.RATH, "Increase in Flexural Strength of Beams by using FRP Composites" International Journal of Engineering, Science and Mathematics Vol. 6 Issue 8, December 2017 (Special Issue). 